$\ell \cdot$

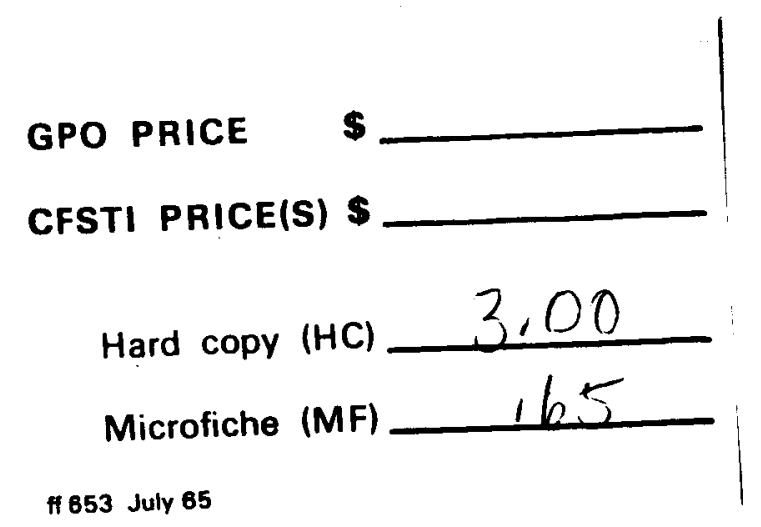

Some Determinants of Organizational Success $†$

by

Frank Stafford*

and

Selwyn W. Becker**
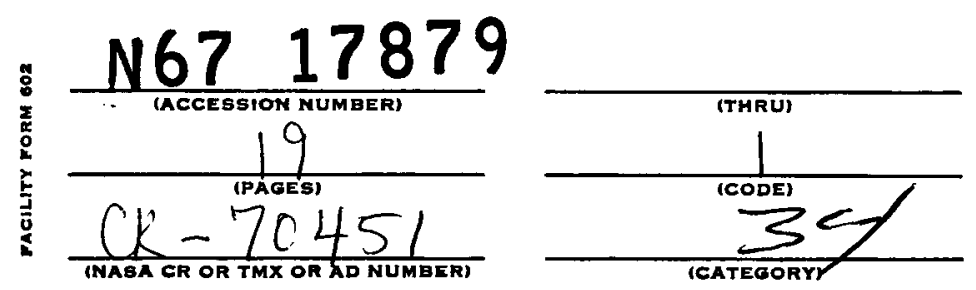

T This research was supported by a grant from NASA, 非s 370 .

*N.O.R.C. Survey Research Fellow, Graduate School of Business, University of Chicago

**Associate Professor of Psychology, Graduate School of Business, University of Chicago

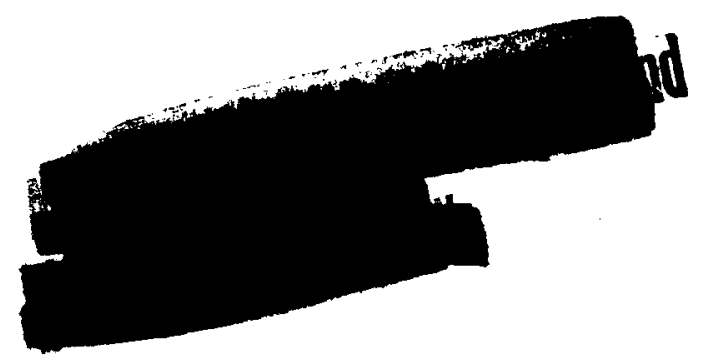




\section{Some Determinants of Organizational Success}

\section{Introduction}

The analysis of formal organizations interests a variety of social scientists. The economist looks at organization size, market structure, and profits, among other things. The sociologist generally focusses on such topics as organization structure, bureaucratization, administrative size, innovation, formal vs . Informal organizations. The psychologist usually restricts his investigation to inter- and intra-group behavior as it occurs within a formal organization. Though their disciplines differ, the interests of these social scientists are not mutually exclusive for each is concerned to some degree with the variables investigated by his colleagues.

Despite this substantial commonality of interests, however, there has been a tendency for the members of one discipline to ignore the literature developed by the members of the other two. Studies relating monopoly position of the firm to rates of technological innovation usually are not known to the sociologist interested in organizational innovation, while the economist interested in growth or opiimal size of firm knows little of the sociologist's work on administrative size or bureaucratization and depersonalization.

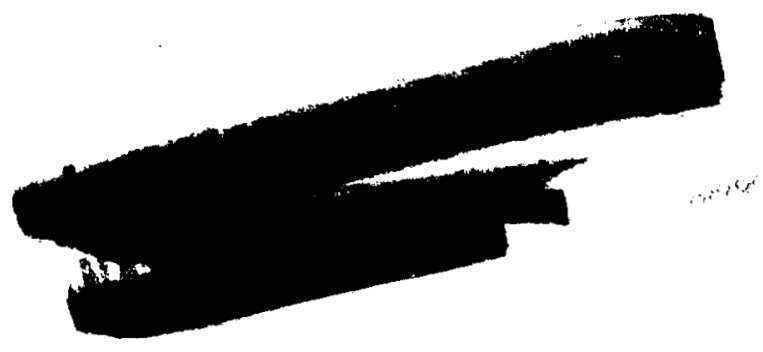


To deplore interdisciplinary ignorance as a matter of course is also to ignore the benefits of specialization and division of labor. However, when interest in a dependent variable cuts across disciplines then ignorance of another discipline's explanatory variables is not defensible on the grounds of specialization. Such a situation seems to exist with regard to the variable, organizational efficiency (profitability, productivity).

Ceteris paribus, the relationship between profitability and the monopoly position of a firm is predictable says the economist. The sociologist, following Max Weber, documents the relationship between bureaucracy and efficiency while the psychologist is still trying to find out why morale sometimes is positively and sometimes is negatively related to productivity. These statements, no doubt oversimplify and misstate the amount of knowledge members of each discipline would claim for themselves. However, they do highlight the fact that each discipline explains the same phenomena with its own independent variable and that no one has bothered to estimate the amount of varlance each explains in the presence of the others. In other words, there has been little attempt to simultaneously ascertain the relative explanatory power of variables from several disciplines. The research reported in this paper is a description of an attempt to measure the relative effect on organization efficiency of variables frequently 
associated with psychologists, economists and sociologists. We want to know how much of the variance in organizational productivity can be explained by organization size, adoption of Innovation, psychological distance in the management team, and environmental state.

\section{Sample}

To measure psychological distance in the management team and the adoption of innovations the chief executives of 183 savIngs and loan associations in Cook County, Illinois were mailed sets of questionnaires with the request that they complete one questionnaire; distribute the others among their management teams (each questionnaire in a personally addressed envelope); collect and return the set to us (without the personally addressed envelope). ${ }^{1}$ Respondents were assured of personal anonymity but since the questionnaires were returned as sets it was possible to associate management teams with particular savings and loan organizations. Ninety-three sets of questionnaires were returned of which 55 were useable. A set was discarded if any members of the set were so incomplete that it was impossible to derive a measure of an independent variable. The 55 sets were compared with the population of saving and loan associations in Cook 


\section{$-4-$}

County with respect to growth of surrounding community, and organization size. (There was a zero response rate in the smallest size class, under $\$ 5$ million, so it was excluded from the analysis.) Seven more associations of appropriate size and commity growth rate were randomly selected and surveyed to make our sample representative of the population with respect to these two variables. The final sample of savings and loan associations thus consisted of 62 organizations.

Two factors affecting this sample are worth mentioning. First, because the associations are all located in cook county, they generally are subject to the economic conditions of one metropolitan area. Second, savings and loan associations in Illinols are prohibited from having branch offices. Consequently, if one is interested in a single unit it is not necessary to isolate it from a conglomerate enterprise. This makes it easier to relate small group variables to any success or productivity measure which might be inferred from annual reports.

\section{The Variables}

A. Dependent Variable. Organization success, efficiency, or productivity is the dependent variable we prefer to investigate. In a group of profit making organizations, like savings and loan associations, net profit is the measure of productivity 
and, In a competitive Industry, of relative efficiency as well. Federal lew covering savings and loan associations prohibits disclosure of net profit data. Accordingly, the proxy selected for net profit (organizational efficiency) was a combination of two values: rate of growth assets; and additions to surplus, both over the three year period of 1961, 1962, 1963. ${ }^{2}$ These two values, rather than either one, were combined as the proxy variable for the following reasons. First, an association can encourage substantial increments to assets by expending energy and resources to solicit new savings deposits. Additions to assets increase Ilablifies to depositors. During the period in which the assets are being Invested a return must be paid to depositors thus reducing surplus. Second, in the short run, an association can ignore new accounts and spend most of its energy loaning available funds at the most profitable rates, thus adding to 1ts surplus. It seems, then, a relatively easy task for a savings and loan association to either grow by adding to assets at the expense of adding to surplus, or to add to surplus at the expense of growth in assets. To both grow and generate increments in surplus is more difficult. Consequently, giving equal weighting to these two factors seems to provide the best proxy for net profit. ${ }^{3}$ Organizational efflclency, whether measured 
as net profit or productivity 18, of course, interesting to economists, soclologists and psychologists.

B. Independent Variables. Our Independent variables differentially attract members of the different disciplines. Surplus as a per cent of assets is of greater interest to economlsts. Association size (assets), community growth, and adoption of Innovations interest economists and sociologists as well as psycholog1sts. Psychological distance in the managerial team more frequently 18 assoctated with psychologists. 4

Organlzation size was measured by averaging assets over the three years 1961-1963. A three yenr average was used to dampen transitory year to year variations. (This is a measure of absolute size and 80 differs from the measure, rate of change of assets, which makes up part of the dependent varlable.)

Surplus as a per cent of assets was considered an Important variable because it is a rough measure of past profit ability and so could be expected to explain some of the variance in our dependent varlable. This measure, too, was averaged over the years 1961, 1962 and 1963.

Adoption of innovations was measured by constructing an Innovations Index from responses given by the association manager. In answering the questionnalre sent to him each manager Indicated 
which of 19 Innovations were adopted by his organization and the year they were adopted. The index was constructed by identifying the year by which $50 \%$ of the associations had adopted a particular innovation. Based on this split an organization could be classed as an early or late (non)adopter for each of the 19 Innovations. A value of 1 was assigned to early adopters and a value of zero to late or nonadopters on each innovation. The sum of the scores was our index of adoption of innovations. Community growth was measured as the ten year increment in population from 1950 to 1960 in the association's census tract area or suburb. 5 Population is an important source of potential savings, so changes in population were expected to effect the measure of success. This is espectally true of savings and loan associations since they are not free to locate where they wish. Locating too near other savings and loan associations is restricted by the Federal Home Loan Bank Board.

The Independent variable, psychological distance in the management team, requires some discussion. Fiedler ${ }^{6}$ originally devised a measure he cailed assüued similarity of others (ASO), which was based on an individual's ratings of his most preferred co-worker (MPC), and least preferred co-worker (IPC). This measure was applied to leaders of small and not 80 small groups 
In a variety of situations. These researches are summarized In an article by Fledler ${ }^{7}$ wherein he concludes that leaders' ASO (and LPC) scores are related to successful group performance. The direction of the relationship varies apparently with the group task. Sometimes group performance is more efficient under managing, directive leaders (high LPC score) and other times effective group performance is related to permissive, accepting leadership (low LPC score).

Fiedler explains these findings in terms of task structure, affective leader-member relations, and leadership power position. 8 With our sample it would have been enormously difficult to obtain measures of these variables so we looked for an alternative explanation of efficient group performance. We reviewed the Items which make up the LPC scale and it appeared to us that some of the items required ratings of task oriented activity while others required judgments about socio-emotional relationships. If this were indeed the case then perhaps much of the conflicting data could be explained more parsimoniously by these separate factors than by Fledler's contingency model of leadership. To test the validity of this reasoning we first hypothesized that a factor analysis of the items making up the IPC scale would yield two factors, task factor ( $T$-factor) and a socio-emotional factor ( $E$-factor); 9 and secondly that in a profit making 
organization the task factor would have greater relative importance than the emotional factor. ${ }^{10}$ In the sense that we expect these two factors to be differentially related to structurally different group tasks we are at least partlal subscribers to Fiedler's contingency model of leadership.

Another major difference between Fledler's and our use of LPC measures is that he applied them to a single leader in each group while we measure psychological distance across a team of managers (leaders). In a formal organization all managers perform some leadership functions so if LPC scores of leaders are related to group productivity then in a formal organization LPC scores of all managers, rather than the chief executive alone, are relevant. Accordingly, for our LPC measure we averaged the responses of all the managers from each association and so derived an LPC score for the managerial group of each organization.

In summary, then, we use rate of change in assets and rate of change in surplus as a proxy for our dependent variable, organizational efficiency. We want to examine how much of the variance in organizational efficiency (profitability) is explained by the different independent variables: organization size, growth rate of the surrounding community, adoption of innovations, past profitability and psychological distance in the management team. 


\section{Results}

Having hypothesized that the LPC scores contained two factors, both of which we planned to enter in the regression analysis as independent variables, it first was necessary to demonstrate the existence of those factors. Accordingly, an intercorrelation analysis was performed and the results of that analysis are summarized in Table 1. From an examination of the intercorrelations of emotional vs.

emotional items it can be seen that for 20 of 28 correlations $r>.35$; and that for 25 of 28 correlations of task vs. task items $r>.35$; while only 11 of the 64 intercorrelations between task and emotional items have an $r>.35$. Because the correlations across all the items are positive one cannot conclude that the two factors are independent of one another. After comparing the correlations within and across the positive factors, however, we suggest that there are two relevant dimensions. Addftional support for this conclusion can be found in the results of the regression analysis presented below.

Mean scores of the management team were calculated for each of the 62 organizations on both the $T$ and $E$ factors then. Next, a stepwise regression analysis was performed to determine how much of the variance in our proxy measure of profitability was explained 
by past profitability (per cent of assets in surplus); adoption of innovations; growth of surrounding comunity; size of organization (total assets); and the $T$ and $E$ factors of psychological distance in the management team.

Based on the results of the analysis presented in Table 2, it can be seen that the $T$ and $E$ factors are important determiners of organizational efflciency. 11 Both factors have coefficients which - - - - - - - - - - -

Insert Table 2 about here

remain relatively stable throughout the steps and both have significant $t$ - values. Further, when the E - factor entered the regression the standard error and $t$ - value of the $T$ - factor remained stable, indicating an absence of multicollinearity. The absence of multicollinearity lends support to treating the $T$ and $E$ factors as separate Independent variables.

Growth of the surrounding community is a measure of how nurturant the environment is since many savings and loan associations draw most of their depositors from their own neighborhoods. Accordingly, it was not surprising that this variable explained a considerable amount of the variance in profitability. What was surprising is that adoption of innovations; past profitability (per cent of assets in surplus); and organization size (total assets) explained virtually no variance in profitability. 


\section{v. Discussion}

Determining the relative explanatory power of the independent variables was the major purpose of this study. That we have achieved some part of that purpose is evidenced by the results of the regression analysis. What is also evident and important is the amount of unexplained variance, despite the use of presumably powerful variables traditionally associated with organization success. Such a situation could possibly arise because our operational measures of short run profitability, organization size and adoption of innovations are ineffective. (If this is true for any of the three variables the best candidate is adoption of innovations. Our index of adoption includes an arbitrary decision on how to combine time and number of adoptions.) On the other hand, the unexplained variance could be due to existence of more important determiners of organization success and surely, other such variables will be proposed. The important point, we feel, is that any proposed variables should be investigated not in isolation, but in the presence of variables known to have some explanatory power.

Of the three we found to have explanatory power, community growth requires least discussion. It seeñs añ obvious relationship. A savings and loan association generally draws savings accounts from its immediate neighborhood. A faster growing nelghborhood means relatively more savings and thus more cash for the association to 
invest. Therefore, certeris paribus a faster growing neighborhood is positively related to profitability.

Our use of the LPC scales is worth discussing for two reasons: a) their use across management teams rather than for just a single group leader; and b) the identification of the task and emotional factors. Group structure emerges over time. In a formal organization this structure is such that leadership functions are performed, albeit differentially, by members of the managerial group. If in a small group the leader's LPC score is related to group productivity, then it seems logical to expect that the success of a formal organization is related to LPC scores across the management team. We compared the mean scores of the chief executive officers to the mean scores of all the other managers to make certain that the effect we found was due to the team score rather than to a single leader's score. On the $T$ and $E$ factors, respectively, the chief executives' mean scores were 9.2 and 10.7, while the other managers' mean scores were 9.5 and 11.7 . The differences easily are attributable to chance. A single demonstration provides little basis for generalization, but we hope that the use of LPC scores across groups of individuals wili provide a new toul in the analyois of formal organizations.

The other interesting finding concerns the nature of the LPC scale. Most frequently personality or attitudinal variables are 
related to LPC scores. Generally, the one who describes his LPC In an unfavorable, rejecting manner is a controlling, task oriented leader rather than a "people oriented" permissive one. We don't argue with this interpretation nor with the evidence supporting it, but we feel that perhaps another relevant dimension has been overlooked. Describing a LPC in unfavorable terms has cognitive as well as emotional aspects. Is it not possible that an individual who behaves this way simply is able to judge the kind of person who would be successful at the group task? In other words, we are suggesting that the IPC score measures an evaluative dimension in the context of formal organizations. The efficient judge of people acts on his judgements and so assembles a group of efficient judges of people for his management team. To the degree that good judgement of others is correlated with organization success, unfavorable LPC descriptions would be related to success.

The findings that LPC scores contain 2 factors and that their use across groups of people is feasible could lead to the development of a model of successful managerial behavior. Such a model might specify the differences in the organization's task structure and how those differences relate to the balance of socio-emotional and task factors in the management team. 
TABLE 1.

CORRELATION MATRIX (LPC ITEMS)

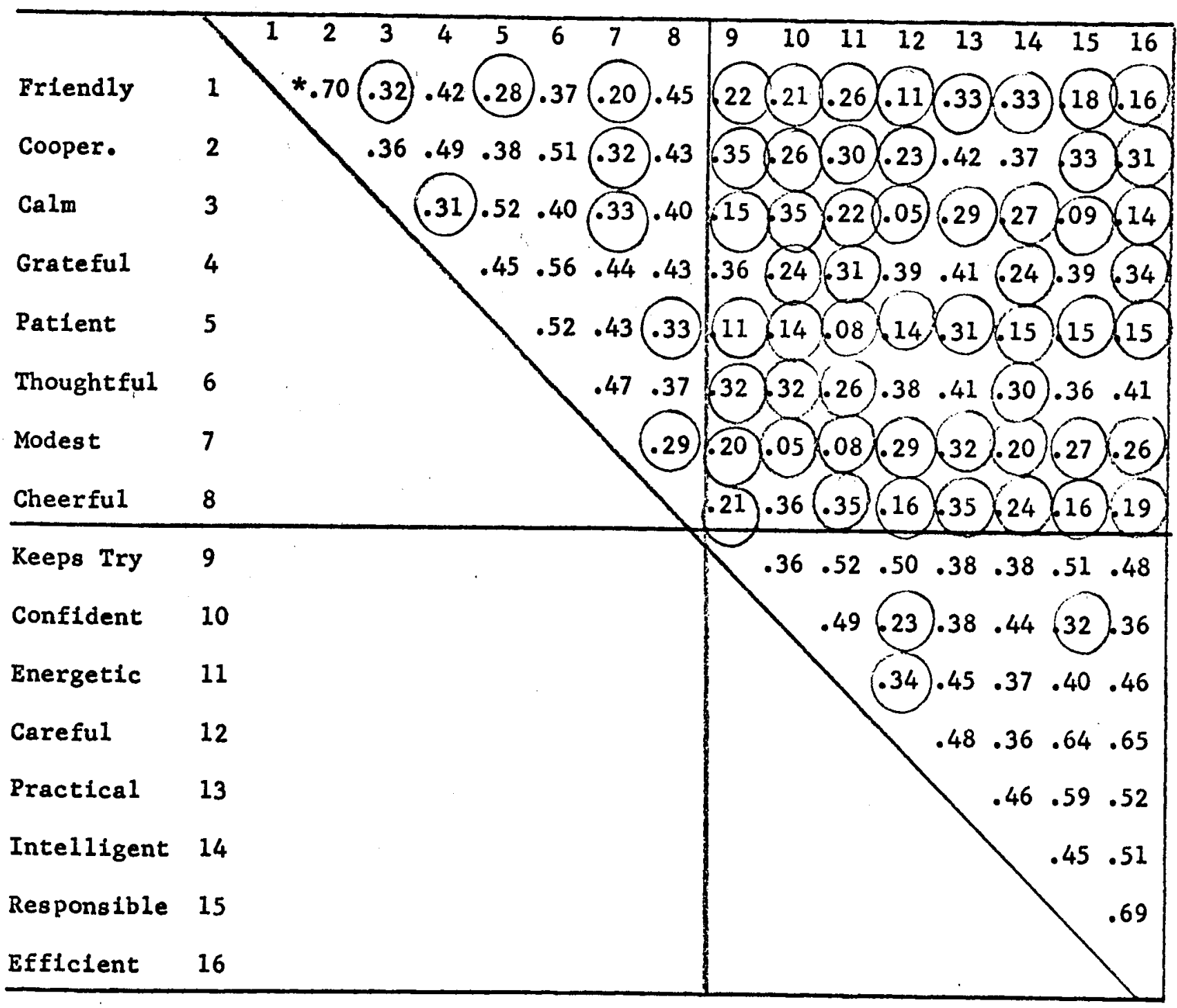

Mature

*uncircled numbers $r>.35$

Bold

Frank

items which exhibited no consistent correlational pattern

Easy Golng 


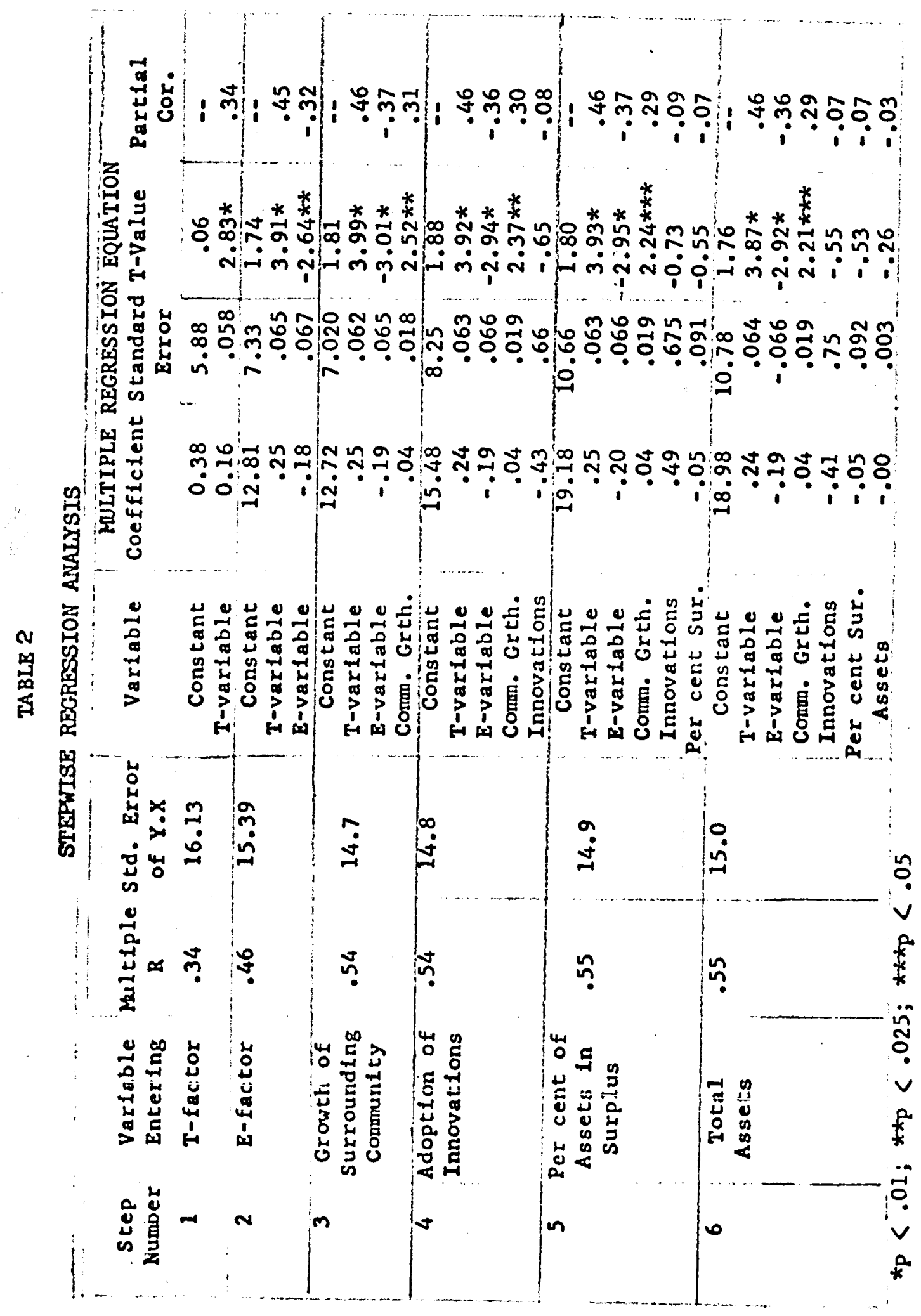




\section{FOOTNOTES}

$1_{\text {These demands on the chief executives could be made only be- }}$ cause of the aid, advice, and publicity given us by Mr. Warren Purse11, Director of Research of the Cook County Council of Insured Savings and Loan Associations.

2 These data were taken from published balance sheets. ${ }^{3}$ Sidney Davidson and David Green, Jr., Professors of Accounting, University of Chicago, and Warren Pursel1, Director of Research Cook County Council of Insured Federal Savings and Loan Associations all concux in this judgment.

${ }^{4}$ Our use of psychological distance is relevant to the economist to the extent that psychological distance is related to the economist's conception of entrepreneurial ability.

${ }^{5}$ Kitagawa and Taeuber, Local Community Fact Book: Chicago Metropolitan Area, 1960.

6iedler, Fred E., "The Leader's Psychological Distance and Group Effectiveness," in Group Dynamics--Research and Theory, Dorwin Cartwright and Zander (editors) (Evanston, Illinois: Row Peterson and Company, 1960)

7Fiedler, Fred E., "The Contingency Model: A Theory of Leadership Effectiveness" in Basic Studies in Social Psychology, Harold Proshansky and Bernard Seldenberg (editors). (New York: Holt, Rinehart and Winston, Inc., 1965). 
${ }^{8}$ Fiedler, Ibid.

9 Fiedler, in a personal communication, indicated that he factor analyzed ASO scales but that his data never allowed him to conclude that there were separate factors. This might perhaps be due to the smal1 N Fiedler had to work with. Even if he used 15 groups, he only had 15 leaders, whereas surveying 62 management teams gave us 323 respondents.

10 A similar theoretical position is taken by Bales and Parsons. Parsons, Talcott and Robert F. Bales, Family, Socialization, and Interaction Process. (Glencoe, Illinois: The Free Press, 1954); Parsons, Talcott, Robert F. Bales, and Edward A. Shils, Working Papers in the Theory of Action. (Glencoe, Illinois: The Free Press, 1953).

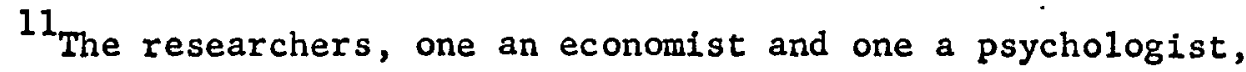
both were surprised by these results. 